\title{
Developing and Evaluating an Adaptive Business English Self-Learning System for EFL Vocabulary Learning
}

\author{
Yen-Hui Wang \\ Department of Information Management, Chihlee Institute of Technology, 313, Sec. 1, Wunhua Road, Banciao District, \\ New Taipei City 22050, Taiwan \\ Correspondence should be addressed to Yen-Hui Wang; jessica4753@hotmail.com
}

Received 26 February 2014; Accepted 5 April 2014; Published 5 May 2014

Academic Editor: Her-Terng Yau

Copyright (C) 2014 Yen-Hui Wang. This is an open access article distributed under the Creative Commons Attribution License, which permits unrestricted use, distribution, and reproduction in any medium, provided the original work is properly cited.

\begin{abstract}
This paper developed an adaptive Business English self-learning system for EFL vocabulary learning. The components of word reoccurrence and learner engagement have been built into the system where the amount of unknown word reexposure in various customized texts increases and vocabulary enhancement tasks are added to promote learner engagement with wanted words. To evaluate the system effectiveness on EFL vocabulary learning, the experimental group read system-screened texts with immediate and repeated contacts with individuals' unknown words and performed vocabulary tasks specific to those unknown words, while the control group read online texts without unknown word reoccurrence and vocabulary practice. After one semester, these two groups were measured by one online vocabulary test, and an online user satisfaction investigation was also administered to the experimental group. The study found that the experimental group reading customized texts to reexpose to previously encountered unknown words in different texts along with doing individualized vocabulary exercises performed significantly better in EFL vocabulary learning than the other group. It was also found that the system was appealing for the learners to show positive attitudes toward the use of the system. The study demonstrated that the constructed adaptive Business English self-learning system could effectively promote vocabulary growth.
\end{abstract}

\section{Introduction}

Word learning through reading is one of the most explored themes in second/foreign language (L2/FL) vocabulary acquisition. A considerable number of reading studies have examined the ways to foster vocabulary learning during reading and found gains in vocabulary development (e.g., [19]). It is true that language learners need sufficiently large vocabularies to successfully use a second language and to be able to read unsimplified authentic materials with ease [10]. However, vocabulary acquisition is a complex and gradually developed process, and different approaches (e.g., intentional learning and incidental learning) may have different effects on word learning.

1.1. Intentional Vocabulary Learning. Intentional vocabulary learning refers to learning new words with an explicit focus on learning meaning and form of a word or on form alone. For instance, studying a list of target words and/or doing such word-specific exercises as multiple choices, synonym matching, sentence building, and translation are activities of intentional vocabulary learning [11]. Research (e.g., [10, 12]) has revealed that more intentionally oriented vocabulary learning which engages learners in manipulating lexical items elaborately within or without contexts is effective to lead to great and fast word gains, durable retention, and productive use of vocabulary. According to the Depth/Levels of Processing Hypothesis [13], the more attention paid to a word item and more manipulations involved with the item, the greater chance the item will be learned and kept memorable as well as internalized into her/his mental lexicon. This is supported by some empirical evidence reported by [14] who propose the Involvement Load Hypothesis claiming that learners with higher learner involvement with words (e.g., engaged in filling in missing words in the blanks of the context and writing compositions) perform better learning in vocabulary acquisition than those who see words in a reading text or read marginal glosses. All this seems to 
suggest that greater vocabulary gains come from explicit word manipulations with high learner engagement, from which intentional vocabulary learning takes place.

1.2. Incidental Vocabulary Learning. Incidental vocabulary learning, such as picking up words accidentally during extensive reading, is meaning-based learning in which learners acquire new words from context and their main focus is centered on comprehending the conveyed meaning instead of learning the linguistic features $[11,15]$. The benefits of learning words incidentally from context have been widely acknowledged. The Input Hypothesis [16] claims that comprehensible input is the necessary and sufficient condition for L2 acquisition. In contextual vocabulary learning, word items are presented in meaningful contexts which provide comprehensible language input to help learners learn, in addition to word meanings, contextualized types of word knowledge including the morphological, syntactic, collocational, and pragmatic features of words [17]. In addition, learners usually cannot acquire a new word through only a single word encounter. Extensive exposure to comprehension-based, meaning-centered input which offers multiple meetings with words in diverse contexts benefits learners to acquire words, reinforce fragile initial learning of words, and consolidate various word knowledge [17]. All this makes incidental, receptive word exposure from linguistic context contribute to an incremental process of word acquisition.

\subsection{Vocabulary Learning Integrating Intentional and Incidental} Learning. Although incidental word exposure from context supports incremental vocabulary development, learning L2/FL vocabulary incidentally is found to gain in small quantities $[12,18-20]$ and seems to be more difficult for learners to reach productive levels of mastery as compared with intentional vocabulary learning [10]. It is because that incidental vocabulary learning from context immersing learners in massive exposure to comprehensible input to accidentally acquire words and gain overall textual understanding usually does not involve conscious word manipulations and thus does not generate enough engagement for words to be learned $[12,17]$. Moreover, Schmitt [10] states that words acquired by merely incidental, receptive exposure do require some intentional learning and additional productive practice for those words to be learned to a productive level.

Nevertheless, on the other hand, although greater word learning and productive use of vocabulary are mainly gained as a result of intentional vocabulary learning, both contextualized word exposure and numerous word reencounters are less likely to occur during the course of language-focused, explicit, intentional vocabulary learning where words are often presented in a decontextualized way or in more restricted contexts with limited word recycling. It is, as mentioned earlier, learning vocabulary incidentally through massive exposure to comprehensible language input that is better able to provide meaningful and multiple encounters with words and help develop mastery of multiple types of word knowledge.

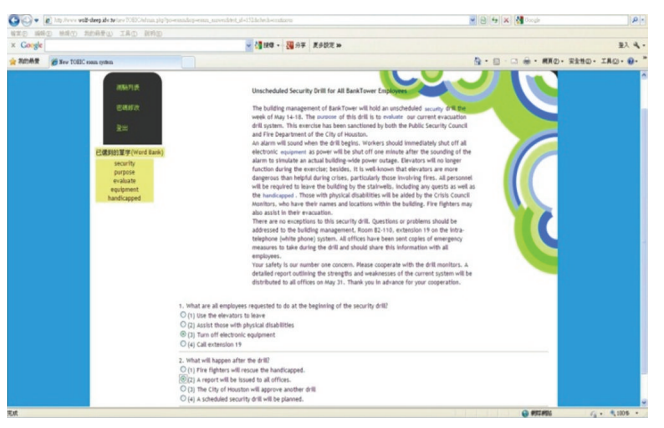

FIGURE 1: Screenshot of a computerized text along with one unknown word list.

Considering all the above, an effective vocabulary learning program may be the one which involves a combination of both incidental and intentional learning modes with each positively complementing the other to maximize learning gains [17]. Therefore, the adaptive Business English selflearning system in the present study was designed to combine an incidental, implicit learning component which provides frequent word reoccurrence and an intentional, explicit learning component which demands deliberate word involvement. More specifically, the system makes use of not only customized reading texts to maximize repeated exposure to individuals' unknown/unfamiliar words but also of postreading vocabulary enhancement techniques to impel learner involvement in word manipulations. This constructed system is in fact a computer-assisted EFL reading system which adds explicit follow-up vocabulary tasks to an implicit vocabulary learning context to create a more favorable condition for second/foreign language vocabulary learning.

\section{Design of the Adaptive Business English Self-Learning System}

The web-based system contains two components: incidental learning and intentional learning. The incidental vocabulary learning part aims to maximize recycling of the unknown words which individual learners encounter while reading. The intentional vocabulary learning part attempts to promote learner engagement with those unfamiliar words. The detailed description of the system is outlined below.

2.1. The Incidental Vocabulary Learning Part. The Text Database of the system consists of 915500 -word computerized reading texts focusing on Business English. Individual learners read the 1st text and use a mouse to click on every single vocabulary that they do not know or are not familiar with. The clicked words are then automatically embedded in individuals' own "unknown word list" placed on the left side of the computer screen (see Figure 1) and stored in the Vocabulary Database. Subsequently, the Knuth-Morris-Pratt string matching algorithm (KMP algorithm) is employed to search for occurrences of those particular words collected in the Vocabulary Database from the remaining texts in the Text Database. Those texts determined by the KMP System to find 


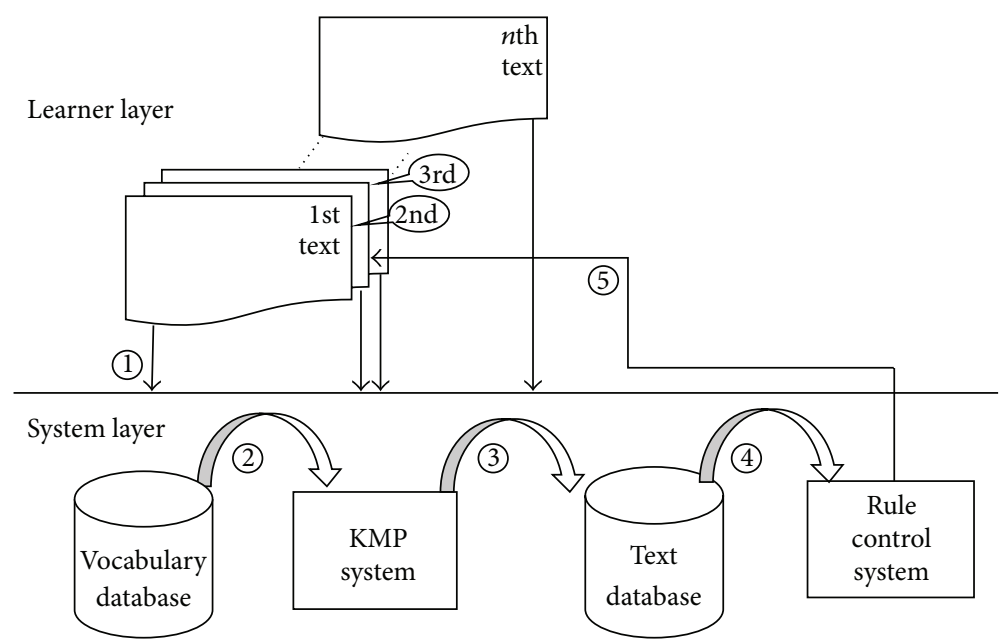

FIGURE 2: System architecture (the incidental vocabulary learning part).

matches in the strings being searched will then go through the text screening process of the Rule Control System which identifies the optimal 2 nd reading text containing as many previously encountered unknown words as possible but with the limit of 5\% unknown words appearing concurrently in one text to assure $95 \%$ recommended known-word coverage. The $95 \%$ criterion was set, following [21]'s suggestion, in order for intermediate-level EFL learners to read with ease and with the need for new word learning. In addition, in the case that more than one text meets such a text screening criterion to be potential reading texts, one, among them, will be randomly selected by the Rule Control System and presented for next reading. Afterward, learners read individual 2 nd customized texts containing the unknown words from the first text and, again, click on any words with which they are unfamiliar. All the unknown words at this point including those being clicked on as unknown ones in the second text (i.e., the currently encountered unknown words from the 2nd text) and those unacquired from the first text and being reclicked on in the second text (i.e., the unknown words from the 1st text which reappear and remain unknown in the 2nd text) form the new unknown word list and are registered in the Vocabulary Database. This new unknown word list serves as the new text screening guideline for the KMP System along with Rule Control System to identify the optimal third text from the Text Database. It should be noted that all the clicked unknown words are in blue highlight while reappearing in the subsequent reading texts so that learners realize when and where to reencounter them. It should also be noted that if those blue highlighted words are not reclicked on by the learner in the text being read, they are already considered as acquired words and are removed from the current unknown word list.

Such a text screening process cycles automatically to generate customized reading texts for personalized vocabulary learning. Figure 2 illustrates the architecture showing the incidental vocabulary learning part of the system. In a word, the system draws on the computer's capacity to screen and identify optimal reading texts with immediate reoccurrence of previously encountered unknown words so that learners read those texts, which are customized to contain particular unknown words that individuals encounter in the previous texts, and are exposed to them frequently in the following texts.

2.2. The Intentional Vocabulary Learning Part. To foster learner engagement for intentional learning, three types of computerized word enhancement techniques, one online look-up device and two online vocabulary exercises, were created. They are detailed as follows.

The system was designed to enable around 95\% knownword level for contextual word guessing for intermediate EFL learners, yet whether learners could successfully infer meaning of each unknown word they encounter is questionable. In addition, results from empirical research have pointed to the usefulness of gloss/dictionary use for vocabulary learning purposes (e.g., [22]). Taking the above two factors into account, it is therefore that the online look-up device (see Figure 3) was incorporated in the system and focuses exclusively on establishing word form-meaning link in order to provide accurate meanings for the individual unknown words that may not be inferred or guessed correctly from context. More specifically, a mouse click over the hyperlink beside the particular word previously displayed in the unknown word list directs learners to access the specific online dictionary that produces L1 translation and L2 paraphrases of the word as well as example sentences using the word.

The second and third vocabulary enhancement techniques are mainly vocabulary consolidation tasks specific to the set of same words presented previously in the online look-up device. Given technical difficulties and learners' limited cognitive capacity, nontedious, decontextualized practice of individuals' unfamiliar words was considered to be both feasible and effective for vocabulary training used in computerized language learning manners with one having learners select the correct spelling of the particular word from three options (i.e., word form recognition task, see Figure 4) and the other requiring learners to type the correct 


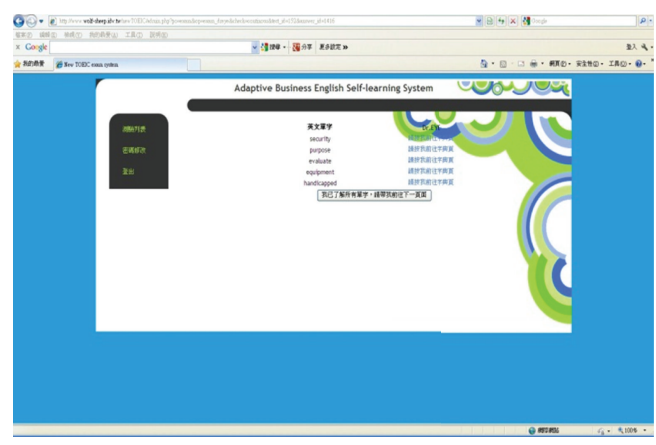

Figure 3: Screenshot of the first vocabulary enhancement toolonline look-up device.

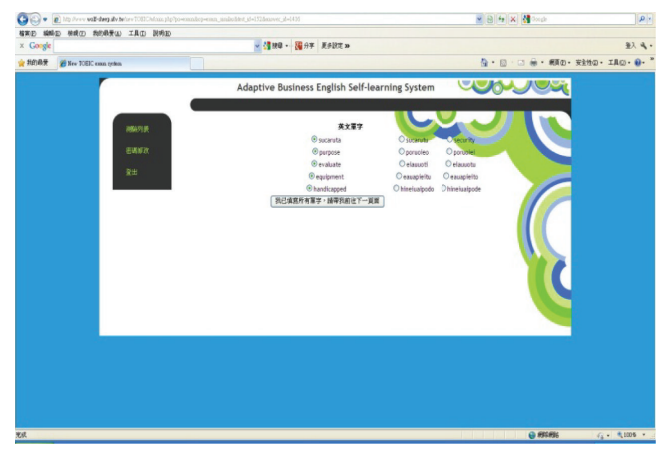

FIGURE 4: Screenshot of the second vocabulary enhancement toolonline word form recognition exercise.

word spelling in the blank (i.e., word form recall task, see Figure 5). Such decontextualized word-focused activities as these two providing conscious lexical manipulations and focusing learners' attention on the isolated words deprived of linguistic context have been reported by some studies to produce positive learning results (e.g., [23, 24]). It is thus reasoned that the two vocabulary enhancement techniques would help promote vocabulary learning performance.

2.3. The Vocabulary Learning Process via the System. The whole vocabulary learning process via the developed system that integrates incidental and intentional learning is sequenced below and illustrated in Figure 6. First of all, individual learners read individual customized texts and use a mouse to click on every single vocabulary unknown to them. The clicked words are then displayed in an unknown word list on the screen. Without online glossaries or online dictionaries provided, learners, at this stage, read texts using contextual inference strategy under an incidental vocabulary learning condition. After reading, learners have to respond to the appended reading comprehension questions and subsequently access the online look-up device to establish initial form-meaning links of those words that are previously clicked on as unknown ones. Once the form-meaning links have been established, it is necessary to consolidate those explicitly learned lexical items with repetition. In addition to the customized texts which offer multiple repetitions specific to individuals' unfamiliar words, both word form

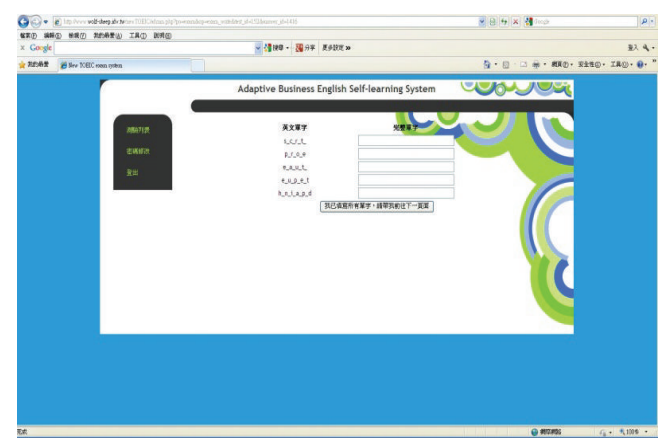

FIGURE 5: Screenshot of the third vocabulary enhancement toolonline word form recall exercise.

recognition exercises and word form recall exercises function to provide engagement-rich word exposure to have individuals encounter those particular words again and manipulate them as discrete items. Upon completion of word-specific practice, it is crucial to enhance the depth of vocabulary knowledge or extend contextual types of word knowledge, which is normally achieved through contextualized, multiple exposure to lexical items. The various customized reading texts generated from the system which adopts the earlier outlined text screening operation are also designed for such a purpose. Following such a text processing and word manipulating procedure, learners read system-screened texts that offer immediate and repeated encounters with the wanted words, click on unknown words in texts, respond to reading comprehension questions, and carry out follow-up vocabulary tasks to expose to unknown/unfamiliar words, experience multiple encounters with the words, get involved in processing those words, and ultimately acquire the words. Schematically, the conceptual framework of the developed system and the learning gains brought about by the system can be shown in Figure 7.

\section{Experiment}

3.1. Participants. To evaluate the effectiveness of the adaptive Business English self-learning system on EFL vocabulary learning, 102 English as a foreign language Taiwanese students agreeing to participate in the experiment were recruited as research participants in the study. All participants were second-year students studying in either the Department of Business Administration or the Department of International Business at one technological college in Taiwan. They enrolled in the Advanced English course which was a required course for sophomores and demanded one-year study of general English. The English proficiency level of these students ranged from lower-intermediate to upperintermediate according to their scores on one TOEIC (The Test of English for International Communication) simulation test administered at the first course session. Based on the stratified random sampling procedure, the 102 participants were assigned into one experimental group (51 students) and one control group (51 students) with each having similar English proficiency. 


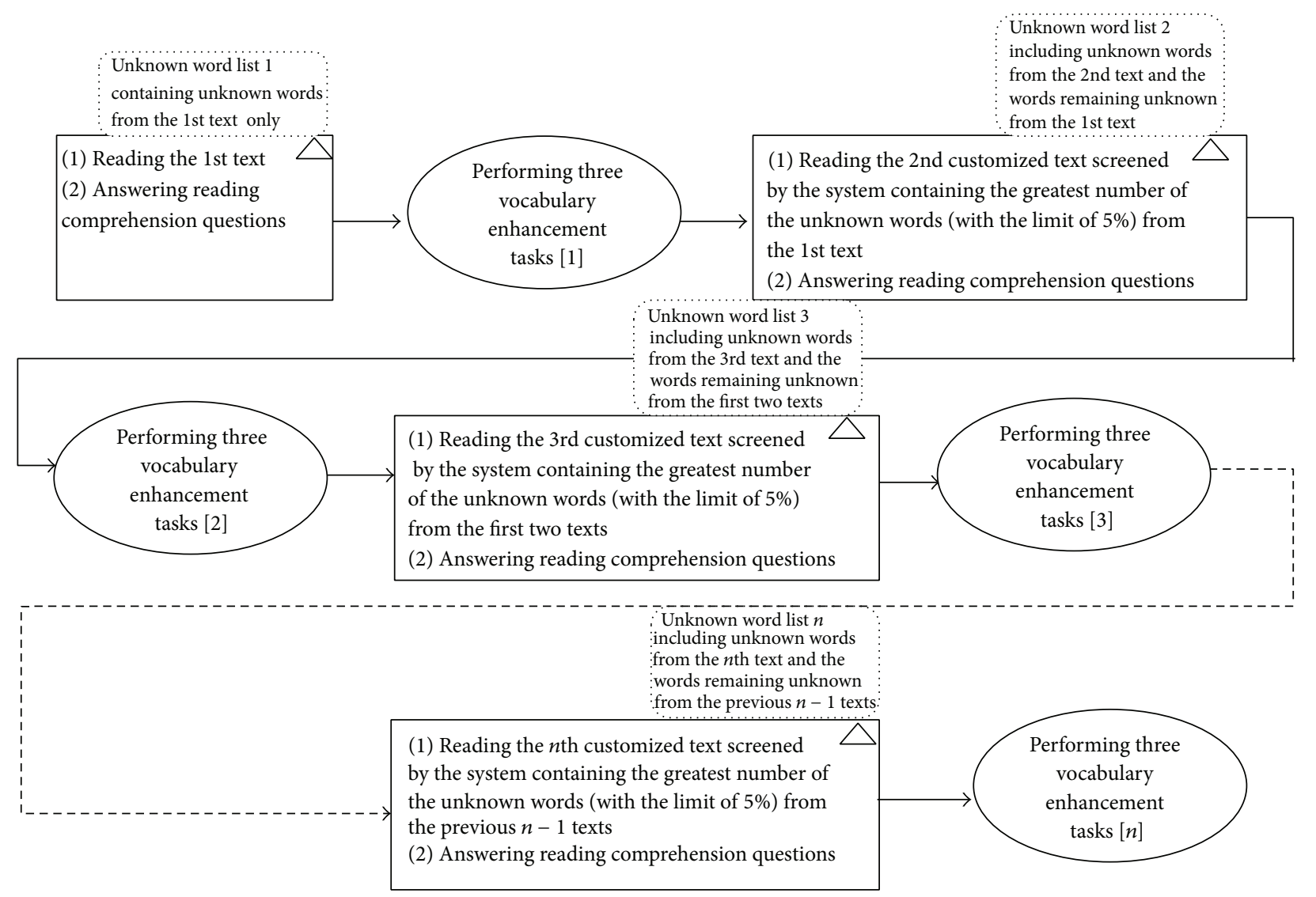

Figure 6: The vocabulary learning process via the system. Note: "rectangle" refers to an incidental vocabulary learning element, and "oval" refers to an intentional vocabulary learning element.

3.2. Procedure. The whole experiment lasted one semester. The course instruction for the two groups was the same, and they were all required to use their usernames and passwords to $\log$ in the system to read five online English texts as assignments after weekly sessions. These two groups were previously offered a technical training session to process online reading. All reading texts that the two groups read came from the same computer database. However, the participants in the experimental group read system-screened personalized texts which offered immediate and repeated contacts with individuals' unknown words and provided word enhancement tasks specific to those words, while the control group participants read scheduled online texts with no control on unknown word reoccurrence and the omission of vocabulary enhancement tasks. It should be noted that the design of mouse clicks on unknown words in the reading condition for the learners in the control group was intended to make the learning context similar to the one in the customized reading condition, but the function of screening particular texts containing clicked unknown words was disabled in the reading condition of the control group. It should also be noted that the database system registered individuals' reading per time and allowed individuals to read subsequent texts without starting all over again upon each different access. All participants' learning processes were monitored from the records of the online tracking system and every student from the two groups had to complete a total of 80 online materials within an instructional period of one semester to ensure that they had had similar amount of online reading from the computer database.

3.3. Measurement. At the end of the semester, the two groups completed one online vocabulary test in which participants were required to key in Chinese translation or an English synonym for each of the 50 English vocabulary items randomly selected, with the aid of computer, from those words that individuals clicked on as unknown ones all through their reading online. In addition, a simple online user satisfaction investigation that followed the vocabulary test was conducted to have the experimental group students indicate the extent of their satisfaction, on a scale of 1 (not satisfied at all) to 5 (very satisfied), with the effectiveness of using the developed system on their vocabulary learning.

3.4. Analysis. To score individuals' answers of the 50 word items measured on the vocabulary test, two points were assigned to each correct synonym/translation with a potential maximum total score of 100 grade points. The means and standard deviations of the data from the two groups were also computed. Also, to test for statistically significant difference between the mean scores of the two groups in vocabulary 


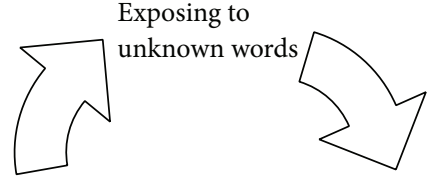

Processing unknown/unfamiliar Reencountering unknown/unfamiliar words elaborately during explicit words immediately and frequently vocabulary practice through customized reading texts

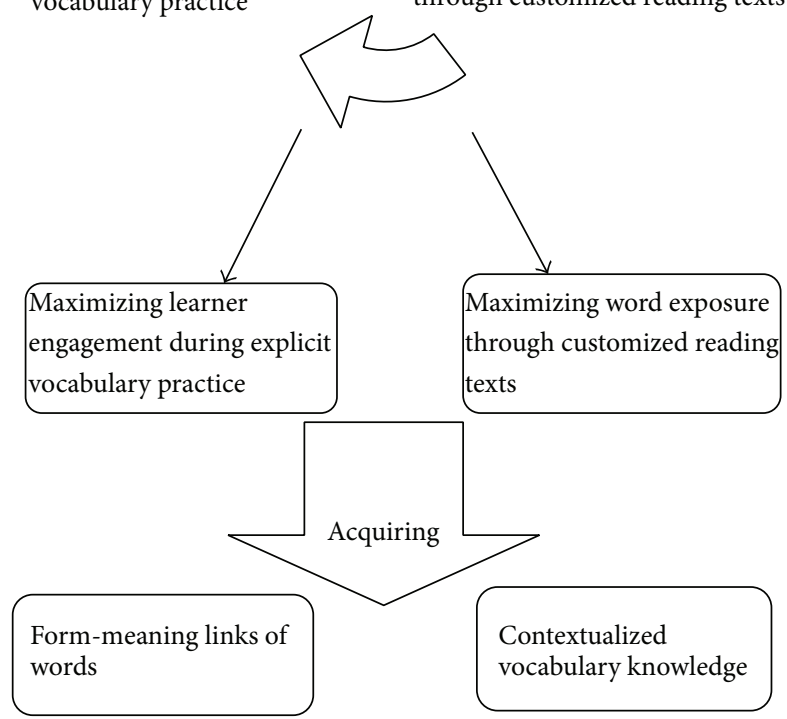

Figure 7: The conceptual framework of the system and the learning gains derived from the system.

learning performance, the Independent-Samples $t$-test was employed. Moreover, the results of the user satisfaction investigation were analyzed using percentages.

\section{Results of the Experiment}

4.1. Effectiveness of the System on Learners' Vocabulary Learning. Table 1 summarizes the mean scores and standard deviations of the vocabulary test results from the two groups. As the table revealed, the vocabulary mean score was $65.80(\mathrm{SD}=4.35)$ gained from the experimental group and $44.94(\mathrm{SD}=4.64)$ obtained from the control group. Table 1 also indicated that the difference between the two groups' vocabulary gains was statistically significant. The test results were compared and illustrated in Figure 8. Such results showed that the experimental group students reading customized texts to reexpose unknown words in different reading texts along with doing individualized vocabulary exercises performed significantly better in EFL vocabulary learning than the students who read online texts without unknown word reoccurrence and explicit vocabulary practice. The results also demonstrated that providing learners with instant and frequent reappearances of unknown words in diverse customized texts and reinforcing their formmeaning connections through postreading vocabulary practice substantially promoted vocabulary growth. The system, therefore, has proved effective to foster EFL vocabulary learning.
TABLE 1: The two group participants' vocabulary score results.

\begin{tabular}{lccccc}
\hline & $n$ & Mean & SD & $t$ & $P$ \\
\hline Experimental group & 51 & 65.80 & 4.35 & -23.435 & $.000^{* *}$ \\
Control group & 51 & 44.94 & 4.64 & & \\
\hline
\end{tabular}

${ }^{*} P<.01,{ }^{* *} P<.001$.

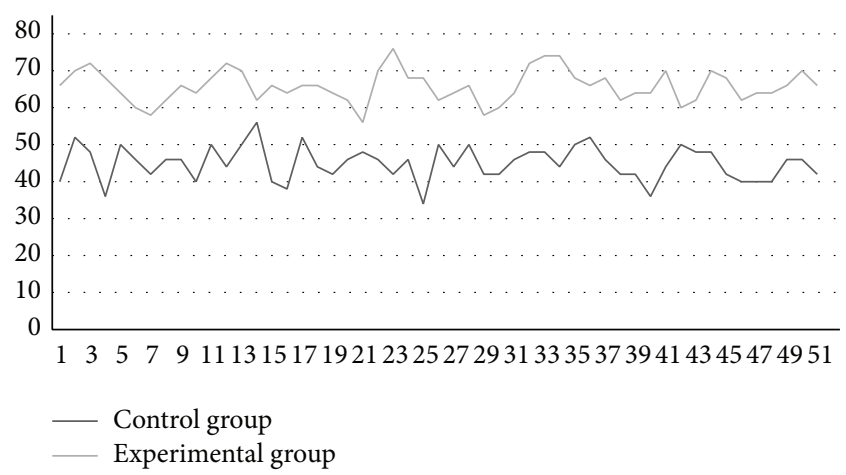

Figure 8: Comparison of the two groups' score results on the vocabulary test.

4.2. User Satisfaction Investigation. In terms of user satisfaction of the developed system, it was encouraging to see from Figure 9 that a great percentage ( $76 \%$ or 39 of the 51 students who rated the numbers 4 and 5 on the scale) of the students in the experimental group responded positively to show a preferable attitude toward their overall use of the adaptive Business English self-learning system, demonstrating that the majority of the learners perceived this system which provides automatic reencounters with individuals' unknown words involved in the customized texts and explicit manipulations of those words demanded by the vocabulary exercises as being effective to promote EFL vocabulary learning.

\section{Conclusions}

This paper developed an adaptive Business English selflearning system which combines incidental and intentional learning for personalized vocabulary learning in English as a foreign language. The components of word reoccurrence and learner engagement have been built into the developed system where the amount of reexposure of previously encountered unknown words in various customized texts increases and vocabulary enhancement tasks are added to impel learner engagement with wanted words. To evaluate the effectiveness of the system on EFL vocabulary learning, two groups of learners read online English texts over one semester with one group reading customized texts to reencounter unknown words immediately as well as engaging in vocabulary exercises and the other reading the texts without unknown word reoccurrence and explicit vocabulary practice. They were subsequently tested by one online vocabulary test. The study found that participants performing customized reading and practicing vocabulary explicitly with the aid of the developed system demonstrated greater vocabulary learning gains as compared with those from the other group. It was also 


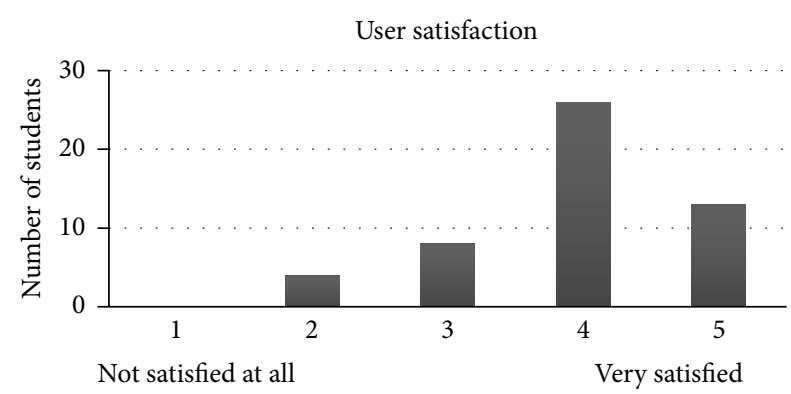

FIGURE 9: Learners' perceived satisfaction with this adaptive Business English self-learning system.

found from an online user satisfaction investigation that the present system was appealing for the learners to show positive attitudes toward the use of the system. It could therefore be concluded that the system which was designed to combine both incidental and intentional vocabulary learning by enhancing word reexposure and learner engagement in the forms of multiple encounters with unfamiliar words involved in diverse customized texts and explicit word manipulations derived from the vocabulary enhancement tasks was particularly conducive to lexical learning. It is expected that the findings of the research would provide language instructors, material developers, and software designers with insights while developing CALL-based (Computer Assisted Language Learning) systems for English vocabulary learning.

\section{Conflict of Interests}

The author declares that there is no conflict of interests regarding the publication of this paper.

\section{References}

[1] R. R. Day, C. Omura, and M. Hiramatsu, "Incidental EFL vocabulary learning and reading," Reading in a Foreign Language, vol. 7, no. 2, pp. 541-551, 1991.

[2] W. Grabe and F. Stoller, "Reading and vocabulary development in a second language: a case study," in Second Language Vocabulary Acquisition, J. Coady and T. Huckin, Eds., pp. 98122, Cambridge University Press, Cambridge, UK, 1997.

[3] M. Horst, "Learning L2 vocabulary through extensive reading: a measurement study," The Canadian Modern Language Review, vol. 61, no. 3, pp. 355-382, 2005.

[4] C. Y. Lao and S. Krashen, "The impact of popular literature study on literacy development in EFL: more evidence for the power of reading," System, vol. 28, no. 2, pp. 261-270, 2000.

[5] $\mathrm{H}$. Liu and $\mathrm{H}$. Wu, "Impact of extensive reading on young EFL learners' vocabulary knowledge, reading proficiency, and motivation for learning English," NPUST Humanities and Social Science Research, vol. 5, no. 1, pp. 1-21, 2011.

[6] B. Mason and S. Krashen, "Extensive reading in English as a foreign language," System, vol. 25, no. 1, pp. 91-102, 1997.

[7] M. Pigada and N. Schmitt, "Vocabulary acquisition from extensive reading: a case study," Reading in a Foreign Language, vol. 18, no. 1, pp. 1-28, 2006.
[8] V. Rodrigo, S. Krashen, and B. Gribbons, "The effectiveness of two comprehensible-input approaches to foreign language instruction at the intermediate level," System, vol. 32, no. 1, pp. 53-60, 2004.

[9] Y. Wang, "Incidental vocabulary learning through extensive reading: a case of lower-level EFL Taiwanese learners," The Journal of Asia TEFL, vol. 10, no. 3, pp. 59-80, 2013.

[10] N. Schmitt, "Instructed second language vocabulary learning," Language Teaching Research, vol. 12, no. 3, pp. 329-363, 2008.

[11] J. Barcroft, "Effects of synonym generation on incidental and intentional L2 vocabulary learning during reading," TESOL Quarterly, vol. 43, no. 1, pp. 79-103, 2009.

[12] B. Laufer, "Focus on form in second language vocabulary learning," in Eurosla Yearbook, H. Foster-Cohen, M. GarciaMayo, and J. Cenoz, Eds., vol. 5, pp. 223-250, Benjamins, Amsterdam, The Netherlands, 2005.

[13] F. I. M. Craik and R. S. Lockhart, "Levels of processing: a framework for memory research," Journal of Verbal Learning and Verbal Behavior, vol. 11, no. 6, pp. 671-684, 1972.

[14] J. H. Hulstijn and B. Laufer, "Some empirical evidence for the involvement load hypothesis in vocabulary acquisition," Language Learning, vol. 51, no. 3, pp. 539-558, 2001.

[15] H. Wode, "Incidental vocabulary acquisition in the foreign language classroom," Studies in Second Language Acquisition, vol. 21, no. 2, pp. 243-258, 1999.

[16] S. Krashen, Principles and Practice in Second Language Acquisition, Pergamon Press, Oxford, UK, 1982.

[17] I. S. P. Nation, Learning Vocabulary in Another Language, Cambridge University Press, Cambridge, UK, 2001.

[18] M. Horst, T. Cobb, and P. Meara, "Beyond a clockwork orange: acquiring second language vocabulary through reading," Reading in a Foreign Language, vol. 11, no. 2, pp. 207-223, 1998.

[19] T. Huckin and J. Coady, "Incidental vocabulary learning in a second language: a review," Studies in Second Language Acquisition, vol. 21, no. 2, pp. 181-193, 1999.

[20] J. Read, "Research in teaching vocabulary," Annual Review of Applied Linguistics, vol. 24, pp. 146-161, 2004.

[21] B. Laufer, "How much lexis is necessary for reading comprehension?" in Vocabulary and Applied Linguistics, P. J. L. Arnaud and H. Bejoint, Eds., pp. 126-132, Macmillan, London, UK, 1992.

[22] J. H. Hulstijn, M. Hollander, and T. Greidanus, "Incidental vocabulary learning by advanced foreign language students: the influence of marginal glosses, dictionary use, and reoccurrence of unknown words," The Modern Language Journal, vol. 80, no. 3, pp. 327-339, 1996.

[23] B. Laufer, "Vocabulary acquisition in a second language: do learners really acquire most vocabulary by reading? Some empirical evidence," The Canadian Modern Language Review, vol. 59, no. 4, pp. 567-587, 2003.

[24] B. Laufer, "Comparing focus on form and focus on forms in second-language vocabulary learning," The Canadian Modern Language Review, vol. 63, no. 1, pp. 149-166, 2006. 


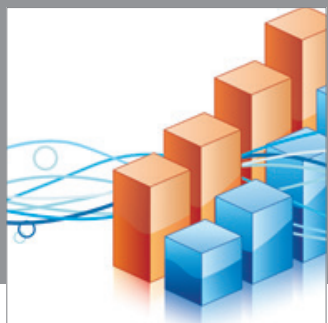

Advances in

Operations Research

mansans

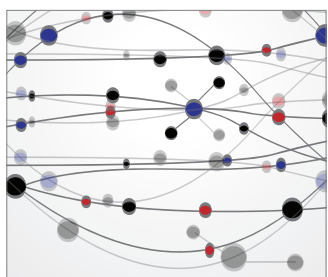

The Scientific World Journal
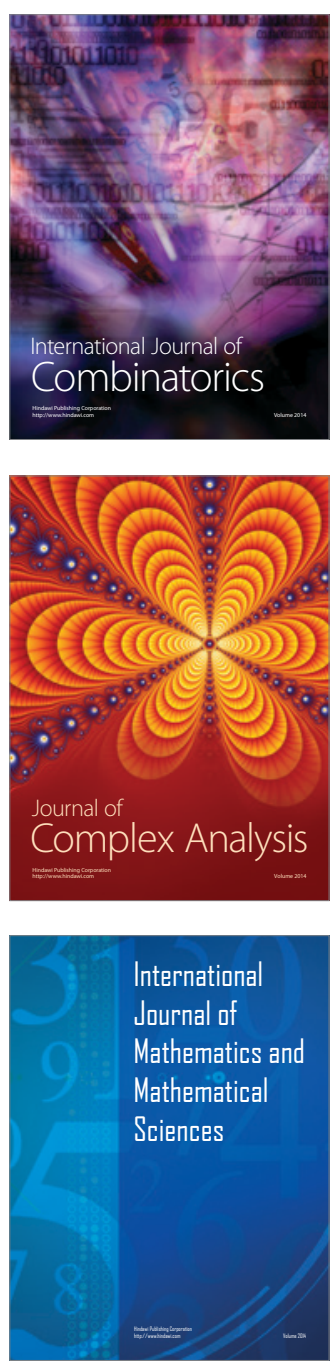
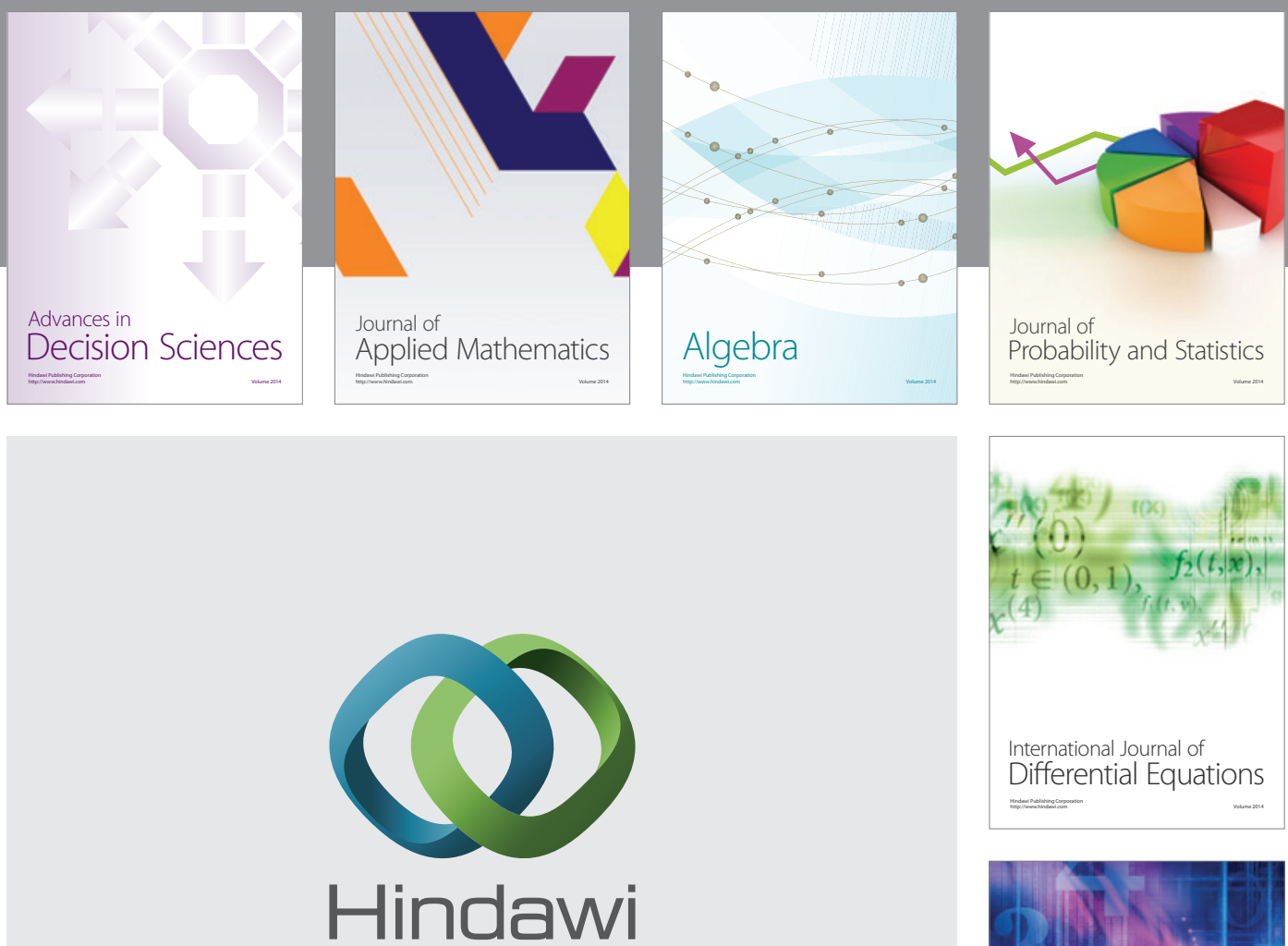

Submit your manuscripts at http://www.hindawi.com
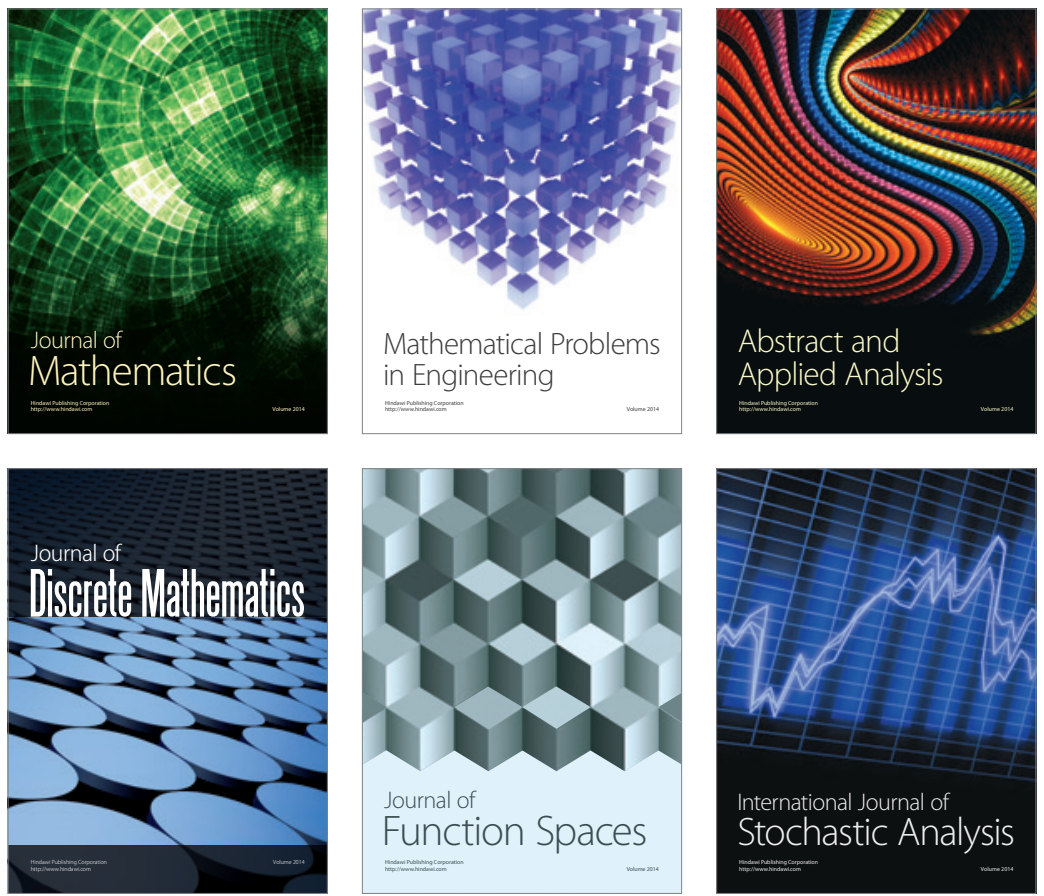

Journal of

Function Spaces

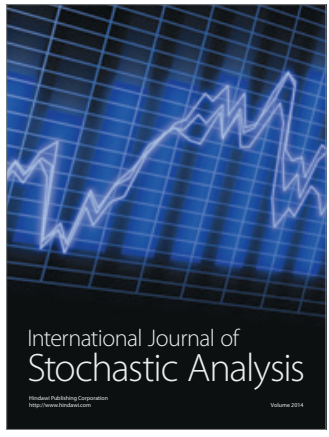

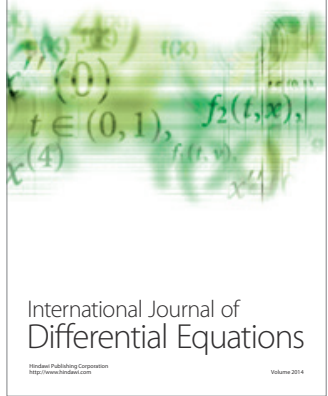
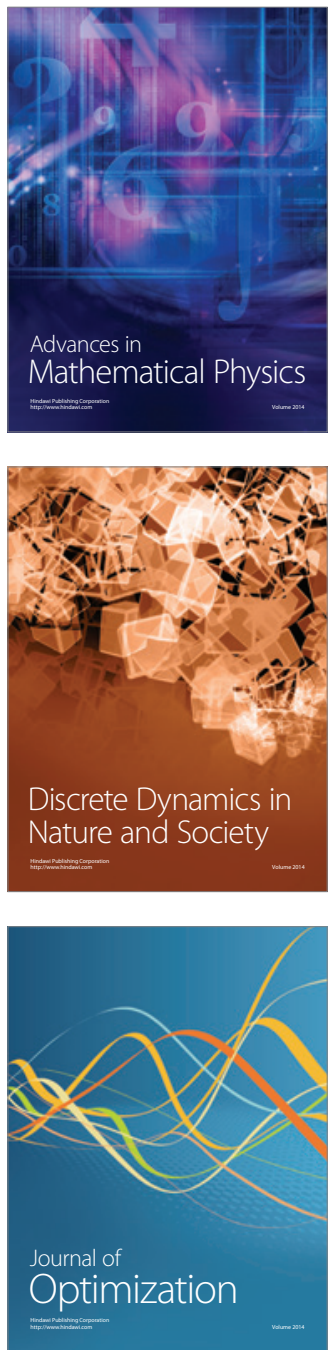